\title{
Reflexões sobre materiais didáticos para alunos surdos: Roma Antiga em Libras ${ }^{1}$
}

\author{
Reflections on teaching materials for deaf students: \\ Ancient Rome in Libras (Sign Language)
}

\section{Reflexiones sobre materiales didácticos para estudiantes sordos: Antigua Roma en Libras}

\author{
(iD) Arlene Batista da Silva \\ Universidade Federal do Espírito Santo (UFES), Vitória, Espírito Santo, Brasil. \\ E-mail: arleneincrivel@gmail.com \\ (iD) Clara Marques Bodart \\ Universidade Federal do Espírito Santo (UFES), Vitória, Espírito Santo, Brasil. \\ E-mail: promessa1401icm@hotmail.com
}

\begin{abstract}
Resumo: Trata-se de uma pesquisa aplicada de produção de vídeos em Libras com conteúdos escolares da disciplina de História. Ancorada nos estudos de Bakhtin (2003) articulados aos Estudos da Tradução (ARROJO, 1992; SOBRAL, 2019, 2008), pretende-se descrever e analisar o processo de tradução do conteúdo audiovisual sobre "Roma Antiga" para Libras. A partir das análises foi possível perceber que os recursos linguísticos, como a incorporação dos personagens, a descrição imagética, a linha do tempo, o uso de classificadores e a contextualização, foram fundamentais para transmitir não somente a informação linguística, mas também informações contextuais, históricas, sociais e culturais que auxiliam a compreensão do leitor.
\end{abstract}

Palavras-chave: Material didático. Aluno surdo. Tradução. Libras.

1 Esta pesquisa foi financiada pela Fundação de Amparo à Pesquisa e Inovação do Espírito Santo (FAPES) por meio do Edital Universal 03/2017 que apoia o projeto "Produções Audiovisuais em Libras" (2018-2020). 
Abstract: It is an applied research of vídeo production in Libras with school contents of the discipline of History. Anchored in the studies by Bakhtin (2003), linked to Translation Studies (ARROJO, 1992; SOBRAL 2019, 2008), we intend to describe and analyze the process of translating audiovisual content about \&quot;Ancient Rome\&quot; to Libras (Sign Language). From the analysis, it was possible to perceive that resources such as the incorporation of characters, the image description, the timeline, the use of classifiers and contextualization, were fundamental to transmit not only linguistic information, but also contextual information, historical, social and cultural that help the reader's comprehension.

Key Words: Teaching materials; deaf student; translation; Libras (Sign Language).

Resumen: Se trata de una investigación aplicada de producción de videos en Libras con contenidos escolares de la disciplina de Historia. Basados en los estudios de Bakhtin (2003), en interfaz con los Estudios de la Traducción (ARROJO, 1992; SOBRAL, 2019, 2008) intentamos describir y analizar el proceso de traducción del contenido audiovisual sobre "Antigua Roma" en Libras. A partir de los análisis, fue posible darse cuenta de que los recursos tales como la incorporación de las personajes, la descripción de los imágenes, la línea del tiempo, el uso de los clasificadores y la contextualización fueron fundamentales para transmitir no solo la información lingüística, sino también informaciónes contextuales, históricas, sociales y culturales que ayudan a la comprensión del lector.

Palabras clave: Material educativo. Estudiante sordo. Traducción. Libras.

Submetido em 05 de maio de 2020.

Aceito em 11 de outubro de 2020.

Publicado em 26 de maio de 2021. 
Reflexões sobre materiais didáticos para alunos surdos: Roma Antiga em Libras Arlene Batista da Silva • Clara Marques Bodart

\section{Introdução}

Atualmente, o contexto educacional constitui-se numa das áreas de maior atuação do Tradutor e Intérprete de Línguas de Sinais-Português (TILSP). É também um campo de trabalho desafiador, pois esse profissional precisa interpretar a aula do professor, de modo que os estudantes possam se apropriar daquele conhecimento, ainda que não possuam noções preliminares do assunto ou domínio da língua de sinais.

Para além da atuação como intérprete, nesse segmento há ainda um campo específico pouco explorado por esse profissional: a atuação como tradutor de materiais didáticos em Libras, pois, habitualmente, o aluno surdo acessa todas as informações em Libras pelo trabalho do TILSP, um importante mediador comunicativo na sala de aula. Sem condições adequadas de trabalho (tempo, espaço físico e recursos materiais) a esse profissional, a tradução do conteúdo escolar praticamente inexiste. O aluno, por sua vez, ao realizar as tarefas de casa, tem no livro didático o único recurso (in)disponível, pois os conteúdos geralmente são expressos em língua portuguesa na modalidade escrita, não respeitando, assim, sua singularidade linguística. Não desconsideramos, aqui, a grande contribuição dos intérpretes no contexto escolar, mas, conforme Silva (2015), ponderamos que a educação de surdos:

[...] precisa trilhar por um caminho diferente das práticas que vêm sendo adotadas, pois, ainda que haja intérpretes nas salas de aula, prevalece um modelo de ensino baseado nos alunos ouvintes. Nesse contexto, o surdo é concebido como um deficiente com recursos: substitui-se o aparelho auditivo pela Libras. Esta, que deveria ser eixo norteador para que o surdo possa se conhecer e se reconhecer em sua alteridade, torna-se, apenas, uma ferramenta para o surdo se adequar na escola dos ouvintes. (SILVA, 2015, p. 21). 
Reflexões sobre materiais didáticos para alunos surdos: Roma Antiga em Libras Arlene Batista da Silva • Clara Marques Bodart

É fato que, a partir de 2005, o mercado editorial vem tentando traduzir materiais pedagógicos bilíngues. A título de exemplo, citamos os livros digitais bilíngues das coleções Pitanguá e Porta Aberta, desenvolvidos pela Editora Arara Azul. Sobre este,

[...] na tradução da COLEÇÃO PORTA ABERTA, mesmo trabalhando com duas equipes exclusivamente de profissionais do Rio de Janeiro, buscamos uma parceria com uma profissional (ILS) que atua em diversas funções no Curso de Letras/Libras da UFSC, além de implantar um AMBIENTE VIRTUAL DE APRENDIZAGEM COLABORATIVA (com possibilidade de mensagens em vídeo) para discussão terminológica e outras, tentando trazer para a Equipe ARARA AZUL a vivência dos alunos surdos e ouvintes que compartilham daquela instituição. (RAMOS, 2013, p. 9).

Já sobre aquele,

No mês de abril de 2007, a equipe que desenvolveu a proposta do LIVRO DIDÁTICO DIGITAL EM LIBRAS fez a proposição de mais um projeto junto à SEESP/MEC: a edição dos 20 volumes da Coleção Pitanguá, editada anteriormente somente em Português escrito e em papel pela Editora Moderna, abrangendo as quatro séries iniciais do Ensino Fundamental, nas disciplinas Português, Matemática, História, Geografia e Ciências. (RAMOS, 2013, p. 7).

Há que se reconhecer, à época, todo o esforço da editora e dos participantes que resultou num feito inédito: a criação de livros didáticos bilíngues distribuídos para as escolas de rede pública nas quais se implementou a política de educação bilíngue para surdos determinada pelo governo federal. Em que pese esse lampejo de acessibilidade, o contexto educacional em 2020 segue às escuras, quando o assunto é material didático em Libras.

O problema se torna ainda mais complexo quando lançamos olhares para o início do Ensino Fundamental II. Nesse nível de ensi- 
Reflexões sobre materiais didáticos para alunos surdos: Roma Antiga em Libras Arlene Batista da Silva • Clara Marques Bodart

no, as mudanças na dinâmica das aulas do $5^{\circ}$ para o $6^{\circ}$ ano causam grande impacto no rendimento dos alunos surdos pelos seguintes motivos: a) maior número de professores e, consequentemente, de diferentes didáticas; b) compartimentação do conhecimento; c) linguagem específica (e desconhecida) de cada disciplina; d) fragmentação do tempo; e e) intérprete de Libras como única forma de acesso às informações em sua língua de instrução.

À luz dessas considerações, pretendemos apresentar uma síntese das experiências vividas no processo de produção de material didático em Libras para alunos surdos do $6^{\circ}$ ano da Educação Básica, com a intenção de colaborar para a construção de conhecimentos significativos na formação de tradutores educacionais. Para tal, tomamos como eixo norteador as seguintes perguntas: a) Como traduzir conteúdos escolares em Libras adequados ao nível linguístico do público surdo "real" matriculado no $6^{\circ}$ ano? b) Quais recursos utilizar para produzir um material audiovisual com uma arquitetônica, nos termos de Bakhtin (2003), que contribua para a aprendizagem dos alunos?

Quanto à natureza, trata-se de uma pesquisa aplicada, pois é comprometida com a inovação e produção de conhecimento científico a partir da prática articulada aos estudos teóricos apreendidos no curso de graduação em Letras-Libras na Universidade Federal do Espírito Santo. O estudo foi desenvolvido em cinco etapas: fase exploratória, tema da pesquisa, coleta de dados, plano de ação, divulgação dos resultados e dos conhecimentos produzidos entre os participantes, conforme será detalhado mais adiante.

Na condução deste estudo, apoiar-nos-emos na perspectiva dialógica da linguagem, em especial no conceito de gêneros discursivos (BAKHTIN, 2003) em articulação aos Estudos da Tradução (ARROJO, 1992; SOBRAL, 2019, 2008). Assim, abordaremos de forma sucinta os pressupostos teóricos acima citados e seguiremos para a descrição e análise da produção dos vídeos didáticos em Libras.

Destacamos, por fim, que esta pesquisa constitui parte do projeto "Produções Audiovisuais em Libras" (2018-2020), financiado 
Reflexões sobre materiais didáticos para alunos surdos: Roma Antiga em Libras Arlene Batista da Silva . Clara Marques Bodart

pela Fundação de Amparo à Pesquisa e Inovação do Espírito Santo (FAPES) por meio do Edital Universal 03/2017. O projeto tem como objetivo principal a produção de materiais audiovisuais em Libras com conteúdos de diferentes esferas sociais (educacional, médica e jurídica). Espera-se como resultado, por um lado, contribuir para a formação de tradutores-intérpretes de Libras mais qualificados para o mercado de trabalho e, por outro, ampliar o acesso dos surdos à informação e a conhecimentos necessários à vida, garantindo-Ihes o direito linguístico.

\section{A interface entre os Estudos da Tradução e os Estudos Dialógicos da Linguagem}

O campo teórico dos Estudos da Tradução já foi (e ainda é) palco de polêmicas em relação à conceituação de seu objeto de estudos. Para alguns teóricos (POPOVIC, 1970; PINCHUK, 1977; NIDA, 1993), a tradução pode ser definida como transporte de significados estáveis. Além disso, compete ao tradutor realizar uma série de procedimentos técnicos para transferir o significado de um texto de uma determinada língua fonte para um texto numa língua alvo.

Em oposição a essa concepção, Rosemary Arrojo, em seu livro Oficina de Tradução: a teoria na prática (1992), defende a tradução como um ato criativo de produção de sentidos em que o texto alvo é influenciado: a) pela leitura do texto fonte feita pelo tradutor e b) pelo contexto linguístico e extralinguístico em que o texto alvo irá circular. A autora assevera que "aprender a ler, significa, portanto, aprender a produzir significados a partir de um determinado texto, que sejam aceitáveis para a comunidade cultural da qual participa o leitor" (ARROJO, 1992, p. 76).

Nessa lógica, o texto traduzido será resultado de múltiplas leituras que o tradutor faz do texto de partida, a saber: a) da leitura feita a partir do texto fonte; b) do público-alvo; c) do contexto histórico e social em que o novo texto será inserido e d) das expe- 
Reflexões sobre materiais didáticos para alunos surdos: Roma Antiga em Libras Arlene Batista da Silva • Clara Marques Bodart

riências, memórias e vivências do tradutor acerca do assunto e do estilo do texto a ser traduzido.

À luz dessas considerações, Arrojo (1992) redimensiona a relação dicotômica que se estabelece entre autor e tradutor, entre original e tradução (como cópia, versão), pois entende, como Jacques Derrida, que "a tradução consiste num processo de modificação de um texto de partida, dando-Ihe sobrevida, por meio das transformações que o tradutor opera nele" (DERRIDA, 1985, p. 226). Ou seja, no ato da tradução, para dar vida ao texto, conferir-lhe imortalidade, o tradutor assumirá, inevitavelmente, o papel de leitor e autor daquilo que interpreta.

Adail Sobral aprofunda a discussão sobre a tradução concebendo-a como atividade de mediação entre culturas, "[...] como atividade que cria conhecimentos ao tornar textos de uma dada cultura acessíveis a leitores de outras, com suas distintas valorações" (SOBRAL, 2019, p. 2). Para o autor, estudos sobre traduções reais revelam que não há traduções exitosas se estas estiverem voltadas unicamente para o autor ou para o leitor, mas "[...] a tradução bem-sucedida é aquela que promove o encontro transcultural entre autor e leitor" (SOBRAL, 2019, p. 2).

Filiado aos estudos dialógicos da linguagem de Bakhtin e seu círculo, o autor defende que a tradução é uma interpretação legítima de um texto em uma determinada cultura que gera sua transposição para outra. Para ele,

A complexidade da interação tradutória advém do fato de essa atividade envolver, em vez de apenas um locutor tradutor e um interlocutor leitor, uma interlocução tradutor-autor e uma interlocução tradutor-leitor de que vem o discurso produzido. Dessa perspectiva, a transposição tradutória é uma complexa operação de mediação entre um autor (que se dirige a um dado leitor, de sua própria língua) e o público a que se destina a tradução (a que o autor não se dirige diretamente) nos termos das relações entre as duas línguas e duas culturas envolvidas. (SOBRAL, 2019, p. 3). 
Reflexões sobre materiais didáticos para alunos surdos: Roma Antiga em Libras Arlene Batista da Silva • Clara Marques Bodart

E, nesse processo de transposição de discursos, entendemos que o tradutor não pode manusear a linguagem e o sentido fora de um contexto e dos sujeitos que dela se apropriam. É preciso, portanto, observar quem diz, o que, a quem é dito, onde e como é dito, para que se possa produzir sentidos. Nessa lógica, concordamos com a ideia de que o resultado da tradução, ou seja, o novo texto criado a partir de um texto fonte é um gênero discursivo à parte, "[...] que constitui vários outros gêneros que origina pelas mãos de um novo autor (ou coautor) um discurso que vem de outro discurso e que já tem um autor" (SOBRAL, 2008, p. 69).

Pensando sobre essas questões, tomaremos como base teórica o conceito de gênero discursivo, proposto pelo filósofo da linguagem Mikhail Bakhtin. Para ele, os gêneros são formados por enunciados que "refletem as condições específicas e as finalidades de cada referido campo não só por seu conteúdo (temático) e pelo estilo da linguagem, ou seja, pela seleção de recursos lexicais, fraseológicos e gramaticais da língua, mas, acima de tudo, por sua construção composicional" (BAKHTIN, 2003, p. 262).

Ancorado nessas ideias, no processo de produção do material didático em Libras é preciso considerar que: a) trata-se de um instrumento pedagógico usado no processo de intelectualização de sujeitos; b) deve conter uma materialidade, uma arquitetônica consoante à cultura alvo; c) deve haver a transfiguração do discurso da cultura fonte para o público-alvo de outra cultura.

Para finalizar, tomamos como princípio a premissa de que a formação de um tradutor torna-se significativa na medida em que esse sujeito alcança uma consciência teórica de sua ação. Nesse sentido, a eleição da matriz teórica dos Estudos da Tradução que concebe a prática tradutória como uma atividade transcultural em detrimento da noção de uma traição ao original foi fundamental para nortear a reflexão crítica sobre todas as etapas de produção do material didático em Libras. 


\title{
Construindo conhecimentos significativos à formação de tradutores de Libras
}

Considerando que esta pesquisa, de natureza aplicada, teve como objetivo central descrever e analisar o processo de produção de material didático em Libras para alunos surdos do $6^{\circ}$ ano da Educação Básica, elegemos como abordagem teórico-metodológica a pesquisa-ação, que segundo Michel Thiollent é definida como:

\begin{abstract}
um tipo de pesquisa social com base empírica que é concebida e realizada em estreita associação com uma ação ou com a resolução de um problema coletivo no qual os pesquisadores e os participantes representativos da situação ou do problema estão envolvidos de modo cooperativo ou participativo. (THIOLLENT, 2011, p. 20).
\end{abstract}

Balizados pelos pressupostos da pesquisa-ação, descreveremos o desenvolvimento do trabalho em cinco fases: 1) Fase exploratória - interação entre pesquisadora e pessoas implicadas na situação investigada; 2) Tema da pesquisa - estabelecimento de ordem de prioridade do problema a ser solucionado por meio de ação concreta; 3) Coleta de dados - pesquisa documental para conhecer o assunto e a materialidade do objeto a ser traduzido; 4) Plano de ação - produção do material didático em Libras; 5) Divulgação dos resultados e dos conhecimentos produzidos entre os participantes.

\section{Estudo exploratório: conhecendo o campo e os sujeitos da pesquisa}

No mês de abril de 2018 foi realizado um mapeamento das escolas-referência da Rede Municipal de Vitória que atendiam a 
Reflexões sobre materiais didáticos para alunos surdos: Roma Antiga em Libras Arlene Batista da Silva . Clara Marques Bodart

alunos surdos no Ensino Fundamental II. Foram identificadas cinco escolas visitadas pela pesquisadora, a fim de promover uma primeira conversa, conhecer a dinâmica de trabalho da equipe bilíngue e as dificuldades em relação ao material didático. Os profissionais relataram que os livros didáticos, muito usados na sala de aula, não possuíam tradução para Libras (CD-ROM, DVD). O que existiam eram materiais adaptados (na maioria das vezes, produzidos pela equipe bilíngue), os quais não davam conta da demanda de conteúdo exigida no Ensino Fundamental II. Pontuaram ainda o fato de os intérpretes atuarem todo o tempo com o aluno na sala de aula, impossibilitando, assim, a tradução de conteúdos para Libras.

\section{Definindo o tema da pesquisa}

Munidos dessas informações, elaboramos um questionário com nove perguntas. Responderam ao questionário quatro professores surdos e três professoras bilíngues (ouvintes). Seis perguntas eram objetivas e tiveram as seguintes respostas: a) formação profissional: pedagogia (4) e Letras-Libras licenciatura (3); b) público com o qual trabalha: surdos, ouvintes e deficientes auditivos (7); c) disciplinas que mais necessitam de tradução para Libras: História (5), Ciências (2); d) o tipo de tradução que facilitaria o aprendizado dos alunos: literal (1), parcial (2) ou adaptada (4); e) tipo de recursos usados da Libras a serem usados na tradução: classificadores (3), descrição imagética (1), os dois itens anteriores mais incorporação e sinais (3) e f) vídeo com ou sem legenda: sem legenda (6). ${ }^{2}$

Houve também três perguntas discursivas. Quanto à importância de se ter materiais didáticos traduzidos para Libras, os professores disseram que tais recursos contribuem para que os alunos possam se apropriar dos conteúdos escolares, garantindo-Ihes mais autonomia. Quanto a sugestões sobre como o texto em

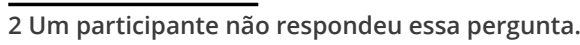


Reflexões sobre materiais didáticos para alunos surdos: Roma Antiga em Libras Arlene Batista da Silva • Clara Marques Bodart

Libras poderia ser sinalizado, seguem alguns comentários específicos: "não fazer uma mera reprodução do texto em português", "primeiramente, ler e compreender o texto, a ideia e só depois traduzir", "traduzir de acordo com o nível linguístico e cultural dos alunos", "fazer uso de ilustrações, imagens, e recursos informáticos". Sobre o uso de outros recursos visuais que possam ser inseridos no material, sugeriram "vídeos e ilustrações claras", "imagens que retratem de forma objetiva o tema abordado, com elementos contextualizadores, por exemplo: colocar a imagem de um objeto no seu contexto de uso".

\section{Pesquisa bibliográfico-documental e coleta de dados}

As respostas dos professores ao questionário foram fundamentais para revelar vários aspectos que precisavam ser levados em conta na elaboração do material didático: a) ter íntima relação com o conteúdo dos livros didáticos; b) ser uma tradução adequada ao nível linguístico-cultural do público-alvo; c) usar vários recursos linguísticos da língua de sinais e não apenas sinais manuais; d) inserir imagens claras que contextualizassem o tema, complementando a informação a ser traduzida. Norteados por essas informações, foi realizado um levantamento bibliográfico a fim de conhecer os livros didáticos da disciplina História do $6^{\circ}$ ano do Ensino Fundamental utilizados em sala de aula pelos professores regentes. Assim, de posse dos livros História: Sociedade \& Cidadania, de Alfredo Boulos Júnior (2015); Para viver juntos, $6^{\circ}$ ano, de Débora Yumi Motooka (2009) e Projeto Mosaico - História, de Cláudio Vicente e José Bruno Vicentino (2016), seguimos com a leitura e descrição objetiva dos conteúdos que serviram como uma das fontes nas quais fizemos uma garimpagem para selecionar as informações que seriam a base da tradução.

Tendo em vista que o currículo de História do $6^{\circ}$ ano abarca uma série de temas, como o conhecimento histórico, a pré-história, a Antiguidade e a Idade Média, houve a necessidade de seleção 
Reflexões sobre materiais didáticos para alunos surdos: Roma Antiga em Libras Arlene Batista da Silva • Clara Marques Bodart

de um conteúdo para a tradução. O tema escolhido foi Roma Antiga, pelos seguintes motivos: a) o conteúdo tinha uma relação com o momento histórico vivido à época (período eleitoral), discussão sobre democracia, justiça etc. e b) tempo exíguo para planejamento, tradução, avaliação, gravação, edição, revisão final e apresentação do vídeo em Libras.

Já de início, surgiu um entrave à tradução. O conteúdo sobre Roma Antiga (texto, imagens, notas explicativas, etc.) nos livros continha cerca de 13 páginas, com textos extensos e poucas imagens. No caso de eleger uma tradução pari passo aos livros didáticos, o vídeo certamente teria a duração de uma hora e meia ou mais. Obviamente, o produto da tradução se tornaria extremamente desinteressante para o aluno surdo. Diante desse problema, resolvemos realizar uma pesquisa documental em fontes audiovisuais, tendo como conteúdo Roma Antiga, a fim de encontrarmos outros modos de planejar o roteiro de tradução, tendo em vista a grande quantidade de informação que precisaria ser condensada de modo que o vídeo em Libras se tornasse um material atraente para o público leitor.

Desse modo, assistimos a diversos vídeos na internet que se configuram como instrumentos didático-pedagógicos que podem auxiliar o tradutor a compreender melhor o assunto. Destacamos, aqui, as produções da TV INES, ${ }^{3}$ do Instituto Phala, ${ }^{4}$ e do Telecurso $2000,{ }^{5}$ que trouxeram grande contribuição para o desenvolvimento desta pesquisa. No programa A vida em Libras da TV INES, a leitura crítica recaiu sobre a composição discursiva de Everaldo Ferreira: uma sinalização lenta, clara e com vocabulário simples da Libras, constituindo um discurso essencialmente didático, que facilita a apropriação do conhecimento. No vídeo do Instituto Phala (vírus Ebola), disponível no Youtube, chamou-nos atenção a tra-

\footnotetext{
3 A TV INES é um canal de TV que veicula conteúdo 100\% acessível à comunidade surda. Por meio da Libras, legenda descritiva e locução transmitem jornais e programas educativos via internet. Cf. http://tvines.org.br/?page_id=1143

40 Instituto Phala é um Centro de desenvolvimento para surdos sem fins lucrativos localizado em Itatiba-SP com o objetivo de oferecer atendimento à saúde, educação, trabalho e assistência social às pessoas surdas da região. Cf. https://www.youtube. com/watch?v=ZHwleJ2G0c0

50 Telecurso 2000 é um sistema de educação a distância mantido pela Fundação Roberto Marinho e pelo sistema FIESP, exibido pela Rede Globo, TV Cultura, TV Brasil e Canal Futura. Foi ao ar de 2 fev. 1995 a 28 mar. 2008. Veicula teleaulas das últimas séries do Ensino Fundamental e do Ensino Médio. Cf. https://www.youtube.com/watch?v=ZbUCsEMkROA https://www.youtube.com/watch?v=ZbUCsEMkR0A\&list=PL-PrFBE9arjBPiEQBDieFrkOV5prLiPvg
} 
Reflexões sobre materiais didáticos para alunos surdos: Roma Antiga em Libras Arlene Batista da Silva . Clara Marques Bodart

dução contextualizadora, em que o tradutor não só apresenta o conceito, mas o explica em detalhes, bem como o uso de imagens ilustrativas que servem como complemento ao texto sinalizado. $\mathrm{E}$ por último, os vídeos do Telecurso 2000, que revelaram a possibilidade de se produzir um vídeo curto com grande quantidade de informações complexas.

\section{Plano de ação: a criação de um novo objeto cultural}

A primeira gravação editada dos cinco vídeos foi feita sem aparatos profissionais, fazendo uso do software de montagem de vídeos "Windows Movie Maker", com simples aplicações de imagens alternadas entre o texto sinalizado. Cada produção abordou um tema (Roma Antiga, Monarquia, República, Alto Império e Baixo Império), seguindo a orientação dos livros didáticos que sistematizavam o conteúdo curricular "Roma" em subtemas, a fim de facilitar a aprendizagem do estudante. Tendo em vista a quantidade expressiva de vídeos, elegeremos como amostra para descrição e análise da pesquisa o primeiro vídeo (Fig. 1), que aborda o tema Roma Antiga.

Figura 1 - Introdução - Roma Antiga, vídeo 1 (1ª versão)

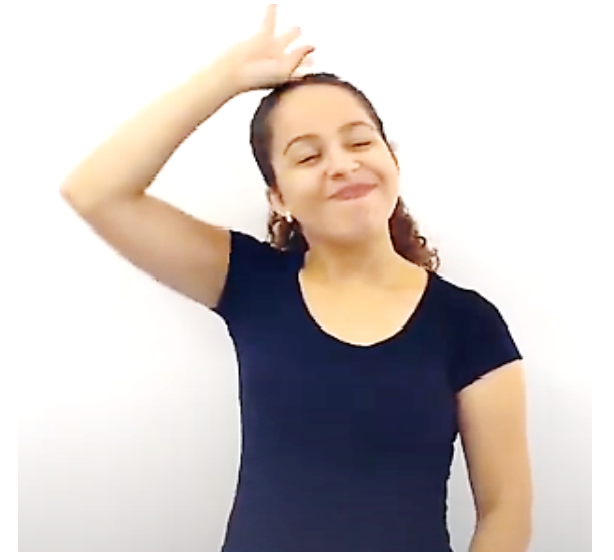

Fonte: vídeo didático em Libras elaborado pela tradutora (2018) 
Reflexões sobre materiais didáticos para alunos surdos: Roma Antiga em Libras Arlene Batista da Silva . Clara Marques Bodart

Figura 2 - Pergunta retórica: “O que é isso?” Vídeo 1 (1ª versão)

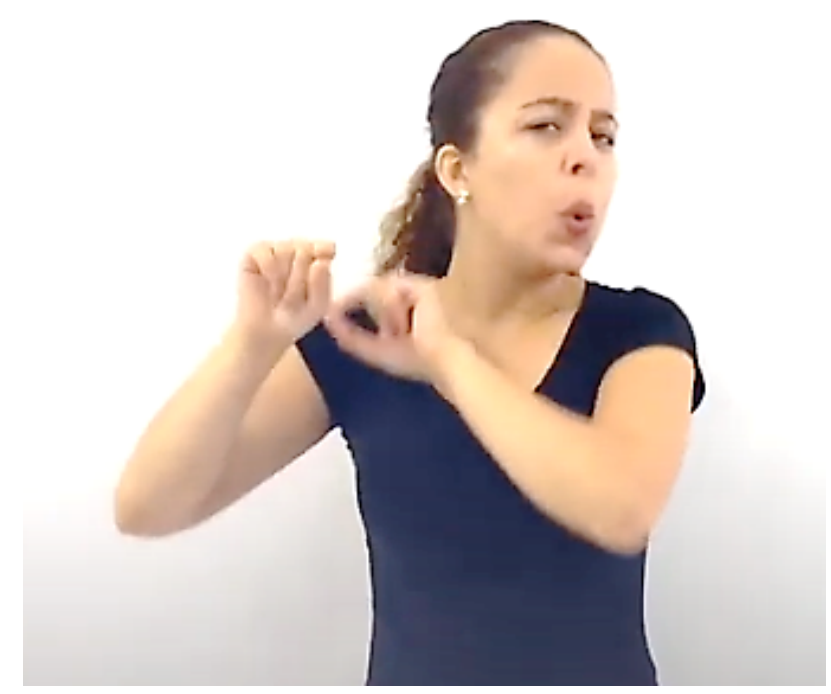

Fonte: vídeo didático em Libras elaborado pela tradutora (2018)

Finalizada a edição, os vídeos foram avaliados pelos professores surdos sobre a forma de realização da tradução do conteúdo sobre Roma Antiga. As sugestões de alteração por parte dos professores recaíram sobre algumas práticas existentes no dia a dia dos TILSP, que exigem reflexão no que se refere à modalidade de sua atuação profissional:

a) redução da velocidade de sinalização da tradutora - situação comum entre os intérpretes, pois precisam ouvir uma informação e interpretá-la rapidamente para acompanhar o discurso do falante sem atrasos;

b) exclusão da pergunta retórica "o que é isso?" - usada antes de apresentar um determinado assunto (Fig. 2); muito frequente quando se quer apresentar, conceituar, descrever um tópico novo que está sendo introduzido no discurso;

c) uso da linguagem adaptada ao nível linguístico dos alunos, com vocabulário comum ao público - é uma tarefa difícil, especialmente quando já se tem fluência e o hábito de se comunicar com surdos adultos os quais utilizam um amplo repertório de sinais; 
Reflexões sobre materiais didáticos para alunos surdos: Roma Antiga em Libras Arlene Batista da Silva • Clara Marques Bodart

d) inserção de mais imagens contextualizadoras (mapas, objetos culturais, espaços sociais como senado, etc.) - esse item chama atenção para o fato de que a maioria dos graduandos do curso Letras-Libras tem suas experiências práticas no campo da interpretação. A criação de materiais audiovisuais exige o domínio de conhecimentos específicos que se referem à pré-produção (roteiro, plano de gravação), produção (chroma key, planos, enquadramentos, iluminação), e, sobretudo, à pós-produção (edição do vídeo - cortes, transições entre cenas, efeitos, construção de diálogo entre o texto e as imagens de forma que se complementem).

É importante ressaltar que a tradutora, desde o início, não seguiu parâmetros ligados à tradução literal, isto é, tradução palavra por palavra, buscando semelhanças estruturais entre as línguas (VINAY; DARBELNET, 1958). Contudo, mesmo que a tradução objetivasse soar como um texto natural, produzido primeiramente na língua e cultura de chegada, havia necessidade de novas modificações para atender ao público-alvo. Portanto, o processo tradutório precisava levar em conta o que é exterior ao discurso: o interlocutor "real", isto é, alunos surdos da Educação Básica em diferentes níveis de conhecimento da Libras (iniciante, intermediário, avançado).

Além disso, era fundamental construir um vídeo em que conteúdo temático, estilo e forma composicional estabelecessem uma harmonia entre as linguagens verbal e visual numa situação concreta de interação, qual seja: ensinar conteúdos escolares a alunos surdos que ainda não dominam a leitura da língua portuguesa e geralmente não possuem conhecimento prévio sobre o assunto. Desse modo, traduzir não pode prescindir a realidade circundante, pois:

[...] entre a primeira e a segunda orientação da obra na realidade (orientação imediata a partir de fora e temática a partir de dentro), estabelece-se uma ligação e uma interdependência indissolúveis. Uma é determinada pela outra. A dupla orientação acaba por ser única, porém bilateral. (MEDVIÉDEV, 2012, p. 197). 
Reflexões sobre materiais didáticos para alunos surdos: Roma Antiga em Libras Arlene Batista da Silva • Clara Marques Bodart

Sob essa ótica, evidenciou-se a necessidade de reflexão sobre a prática tradutória e de construir conhecimentos significativos a partir das condições de produção sociais e culturais que se apresentavam diante da feitura do material didático. Desse modo, foram eleitas algumas escolhas tradutórias (acréscimos, omissões) em relação às linguagens verbal e visual na segunda versão dos vídeos, as quais apresentaremos a seguir.

\section{Figura 3 - Geolocalização de Roma - Vídeo 1 (2 ${ }^{\mathrm{a}}$ versão)}

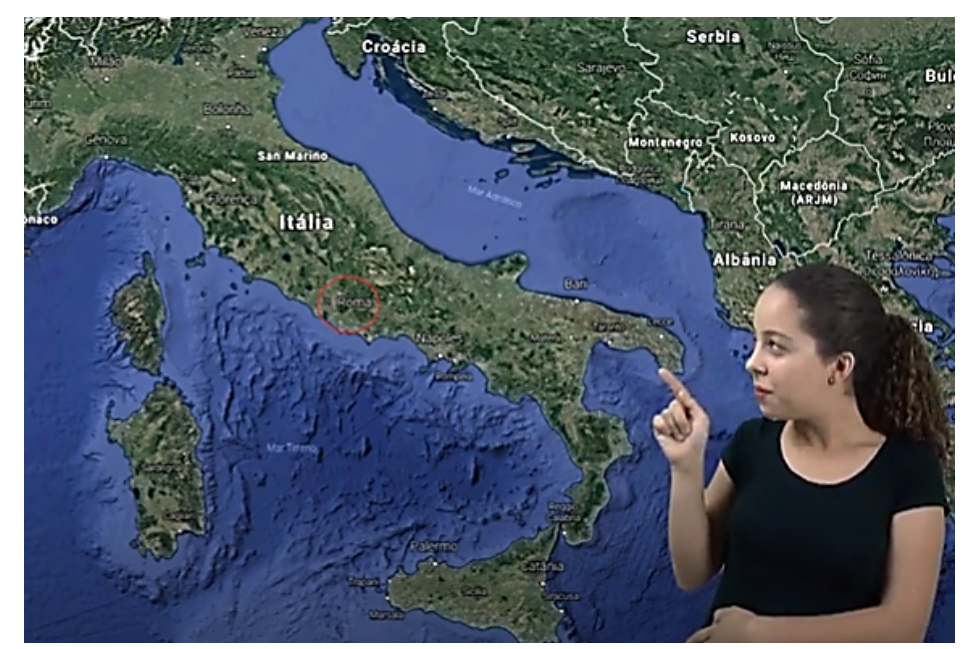

Fonte: vídeo didático em Libras elaborado pela tradutora (2018)

Já nas informações iniciais, foi inserido um mapa como plano de fundo (Fig. 3) para situar o leitor quanto às informações geográficas de Roma. A tradutora foi enquadrada à direita da tela para que pudesse dialogar com as imagens sempre dispostas à esquerda. 
Reflexões sobre materiais didáticos para alunos surdos: Roma Antiga em Libras Arlene Batista da Silva · Clara Marques Bodart

Figura 4 - descrição imagética - vídeo 1 ( $2^{\mathrm{a}}$ versão)

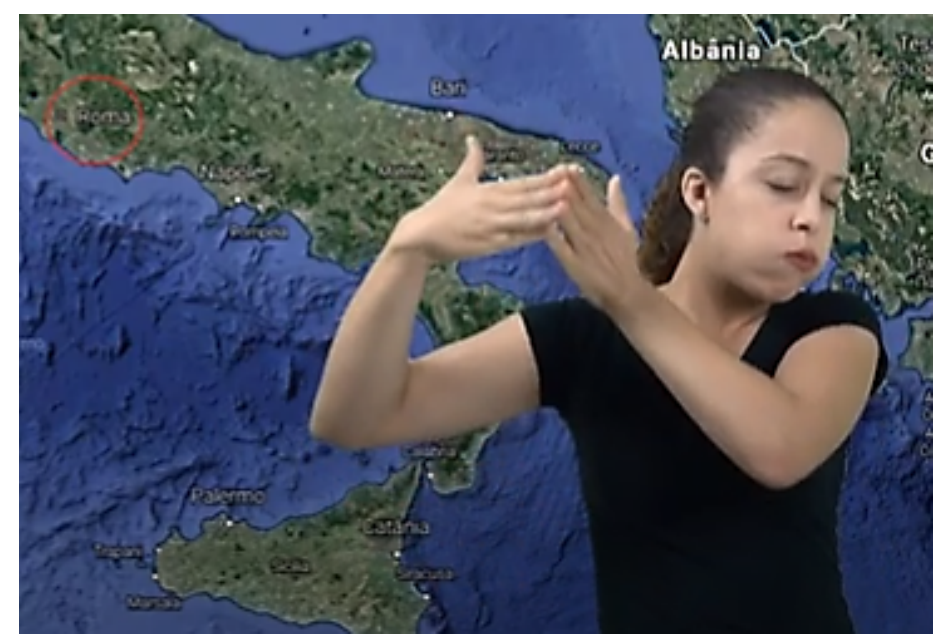

Fonte: vídeo didático em Libras elaborado pela tradutora (2018)

Para traduzir a informação sobre a navegação mercantil (transporte de mercadorias e produtos agrícolas) que ocorria no rio Tibre por meio de um sistema navegável que penetrava toda a região de Roma, a tradutora optou pela descrição imagética (Fig. 4): encenou um barco descendo um rio até chegar à Roma e, em seguida, descreveu as relações de compra e venda de diversos produtos.

Figuras 5, 6 - composição de sinais (COLONIZAR+PEGAR) vídeo 1 (2 ${ }^{\mathrm{a}}$ versão)
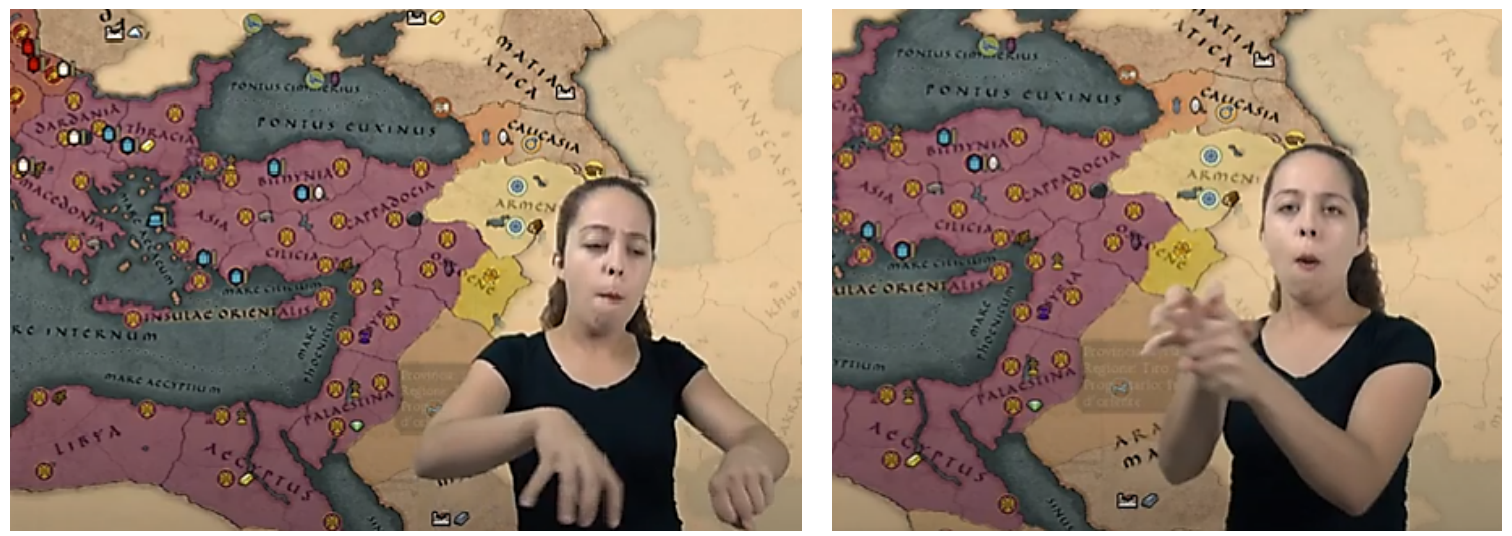

Fonte: vídeo didático em Libras elaborado pela tradutora (2018) 
Reflexões sobre materiais didáticos para alunos surdos: Roma Antiga em Libras Arlene Batista da Silva . Clara Marques Bodart

Outro desafio que se impôs era explicar como Roma expandiu seu território e dominou grande parte da Europa, Ásia e norte da África. A tradutora inseriu um mapa com as delimitações territoriais do Império Romano como plano de fundo e, a partir dele, explicou que Roma conquistou diversas cidades, impondo sobre elas o seu controle por meio da seguinte construção simultânea (Fig. 5, 6): a) junção de sinais (COLONIZAR + PEGAR), b) expressão facial de braveza e c) o movimento labial explosivo por meio da consoante oclusiva na sílaba "pá" repetida diversas vezes (pá, pá, pá). Toda essa operação tradutória sincronizada teve como intento mostrar que Roma expandiu seu território por meio da conquista e apropriação de terras alheias.

Figura 7 - linha do tempo - vídeo 1 ( $2^{\mathrm{a}}$ versão)

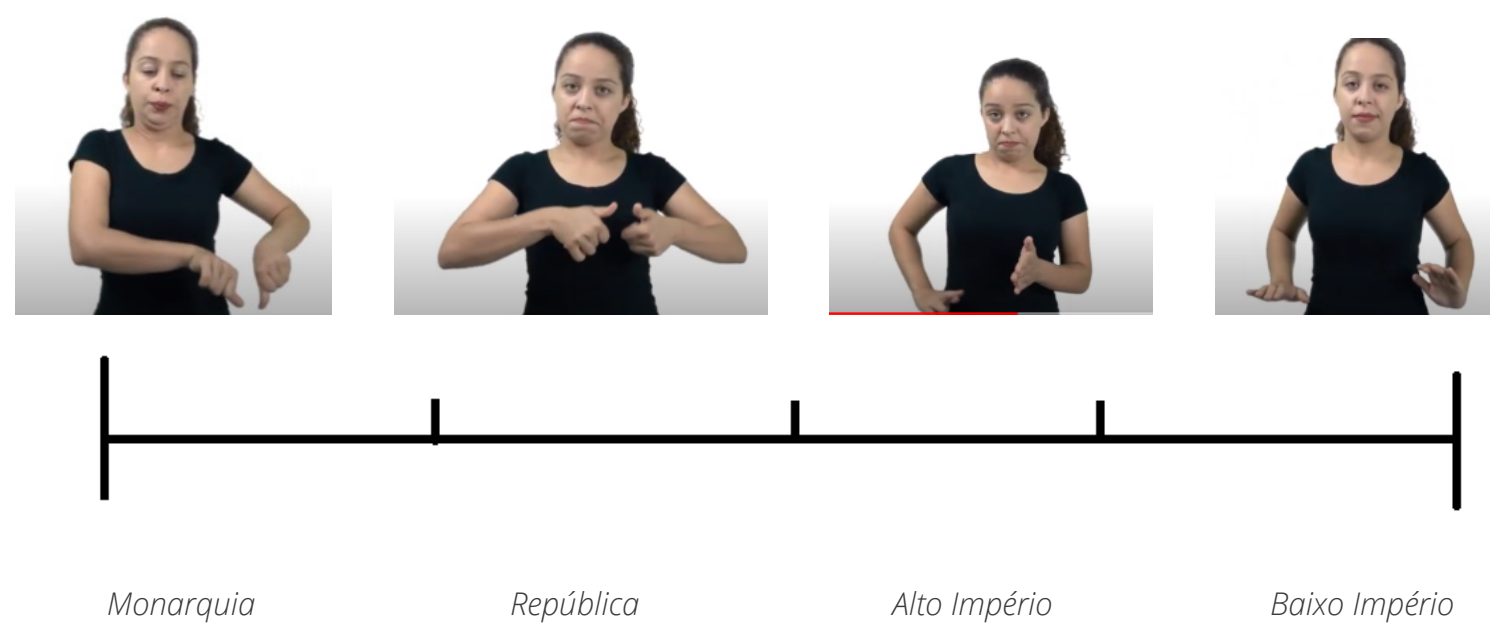

Fonte: vídeo didático em Libras elaborado pela tradutora (2018)

Para explicar diferentes momentos históricos e políticos de Roma, a tradutora construiu uma linha do tempo, posicionando-a à sua frente e, guiada pelos livros didáticos, a dividiu em quatro períodos da direita para a esquerda: Monarquia (sinal REI), República (configuração de mão (CM) em R + sinal GOVERNO), Alto Império (CM em I + sinal GOVERNO + sinal MELHOR), Baixo Império (CM em I + sinal GOVERNO + sinal PIOR), conforme se observa na Figura 7. Como, à época, não foram encontrados glossários com 
Reflexões sobre materiais didáticos para alunos surdos: Roma Antiga em Libras Arlene Batista da Silva · Clara Marques Bodart

sinais que representassem os períodos, a tradutora precisou estudar os conceitos desses enunciados para combinar esses morfemas e construir novos lexemas (FELIPE, 2006).

\section{Figura 8 - role-play: patrício - vídeo 1 ( $2^{\mathrm{a}}$ versão)}

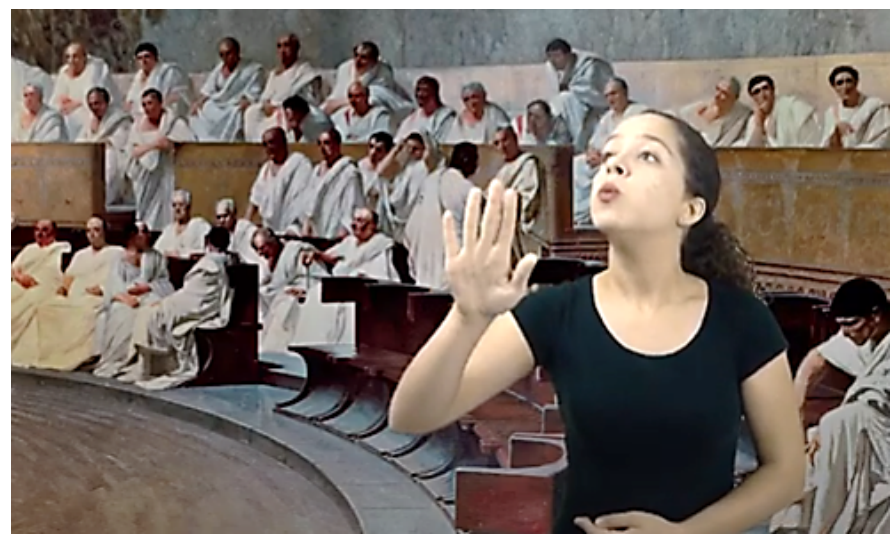

Fonte: vídeo didático em Libras elaborado pela tradutora (2018)

Por fim, uma última análise presente no tema "Monarquia" (vídeo 02) merece realce. Para traduzir a atuação dos patrícios durante as assembleias realizadas no senado, foi escolhido o recurso role-play, isto é, uma encenação, quando o sinalizador assume a posição dos personagens e incorpora suas ações (SOUZA 2009, QUADROS; KARNOPP, 2004; FERNANDES 2003). Tendo a imagem de uma assembleia como plano de fundo, a tradutora olha à sua direita e interpreta um patrício manifestando sua opinião no senado (Fig. 8). Em seguida, volta o olhar para a filmadora, reassumindo a posição de narradora principal, e explica que os patrícios eram os únicos a exercerem benefícios políticos em Roma.

Baseados nessas breves análises, defendemos as práticas tradutórias aqui adotadas como permutações transculturais entre livros didáticos e os vídeos em Libras, sem que isso signifique que o segundo esteja subordinado ao primeiro. Nessa lógica, o que se percebe em todas essas camadas de desconstrução/recriação é o desmantelamento da hierarquia entre original x cópia. Portanto, a tradução atualiza, recria os enunciados sobre Roma Antiga nos ví- 
Reflexões sobre materiais didáticos para alunos surdos: Roma Antiga em Libras Arlene Batista da Silva • Clara Marques Bodart

deos, dando origem a um novo acontecimento, pois, como afirma Bakhtin (2003),

[...] devemos admitir que qualquer oração, inclusive a mais complexa, no fluxo ilimitado da fala pode repetir-se um número ilimitado de vezes em forma absolutamente idêntica, mas como enunciado (ou parte do enunciado) nenhuma oração, mesmo a de uma só palavra, jamais pode repetir-se: é sempre um novo enunciado (ainda que seja uma citação). (BAKHTIN, 2003, p. 313).

Outras contribuições, para além dos discursos dos professores, somaram-se à arquitetônica dos vídeos em Libras. No decorrer da pesquisa, surgiu uma oportunidade de visitar o INES (em juIho de 2018) e contatar especialistas na área de tradução e edição de vídeos da instituição que também avaliaram o material didático que estava sendo produzido. Eles alertaram para o fato de que a redução do tamanho da tradutora em alguns trechos do vídeo para destacar as imagens era um grave equívoco, pois acarreta supressão do conteúdo verbal em detrimento de conteúdo não-verbal, o qual deve assumir função de recurso complementar, sem se sobrepor à informação sinalizada. Anotadas todas essas considerações, foi realizada uma terceira gravação no LABLIBRAS, ${ }^{6}$ para correção e ajustes da segunda versão do material didático.

\section{Divulgação dos resultados: um novo objeto para um novo leitor}

Na última fase da pesquisa, retornamos às escolas para apresentar os materiais finalizados aos membros externos do projeto. Assim, na segunda quinzena de setembro de 2018, os vídeos (terceira versão) foram assistidos pelos professores e alunos, a fim de avaliarem se as correções agregaram valor positivo ao material,

6 Laboratório de Tradução de Libras do curso Letras-Libras bacharelado da Universidade Federal do Espírito Santo. 
Reflexões sobre materiais didáticos para alunos surdos: Roma Antiga em Libras Arlene Batista da Silva • Clara Marques Bodart

no sentido de contribuir para a apropriação do conhecimento por parte do público-alvo.

Após assistirem aos vídeos, foi feita uma roda de conversa e, por meio de algumas perguntas (o que você entendeu sobre o vídeo? Quem eram os personagens tais e tais? Quais eram suas funções em Roma?), buscamos perceber se os alunos surdos haviam compreendido os sentidos da tradução. Pelas respostas, constatamos que eles produziram seus discursos, posicionando-se com clareza em relação aos conteúdos assistidos, resultado do processo de interação com o material audiovisual. Todavia, foi sugerido por parte dos professores um último ajuste às edições de vídeo, sendo: a inserção de legendas em língua portuguesa às soletrações manuais em Libras, para que, ao pausar o vídeo, o aluno surdo pudesse realizar um resgate dos termos expostos.

Diante dessas sugestões, foram feitos novos ajustes na terceira e última versão dos vídeos. Com o apoio de um estudante do curso de cinema que atuava como bolsista FAPES do LABLIBRAS, os cinco vídeos foram produzidos numa interface com imagens no plano de fundo e a tradutora em primeiro plano, localizada à direita, em tamanho grande. Também foi criada uma abertura com símbolos icônicos da cultura romana (Coliseu, soldado romano) para todos os vídeos, de forma a introduzir para os interlocutores o assunto central do material didático (Fig. 9). As imagens, todas de domínio público, foram fundamentais para contextualizar informações geográficas, sociais e culturais de Roma Antiga, contribuindo para o leitor surdo construir sistemas de referência e estabelecer correlações com dados objetivos do mundo concreto. Ao longo de 2020, os vídeos serão divulgados pela plataforma Youtube, ${ }^{7}$ sem restrição de acesso, a fim de que toda a comunidade surda no Brasil possa se beneficiar do conteúdo produzido (Fig. 9, $10,11,12,14)$.

$\overline{7 \text { No canal Na Palma }}$ da Mão. Cf. https://www.youtube.com/channel/UCBsQvVszGY7KdxvbUCMRHfg. 
Reflexões sobre materiais didáticos para alunos surdos: Roma Antiga em Libras Arlene Batista da Silva • Clara Marques Bodart

Figura 9 - abertura - vídeo 1 ( $3^{\text {a }}$ versão)

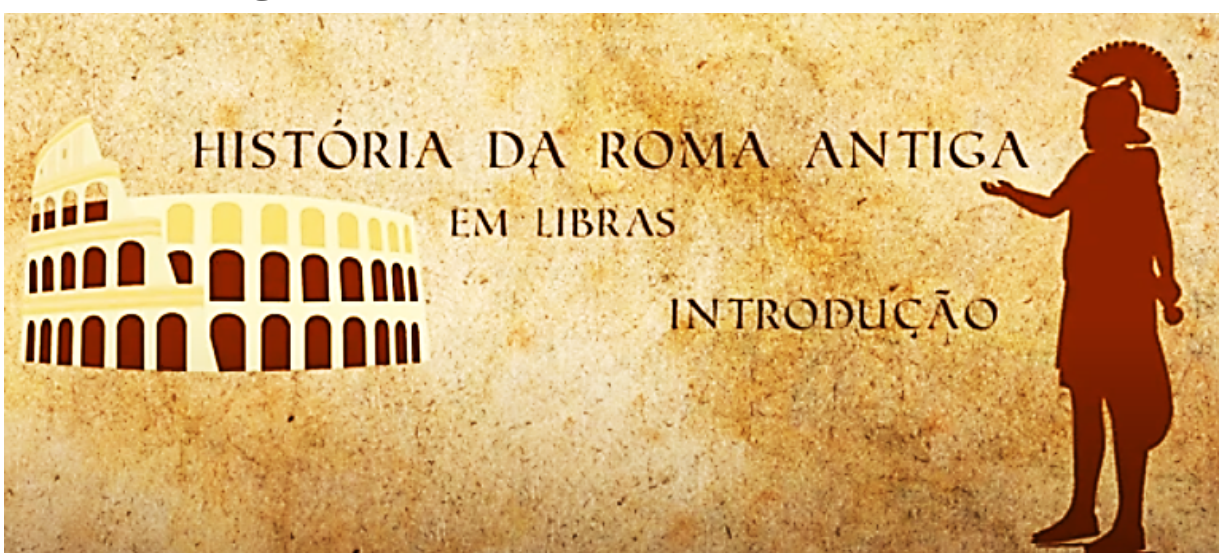

Fonte: vídeo didático em Libras elaborado pela tradutora (2018)

Figura 10 - vídeo 1 - Introdução (3a versão)

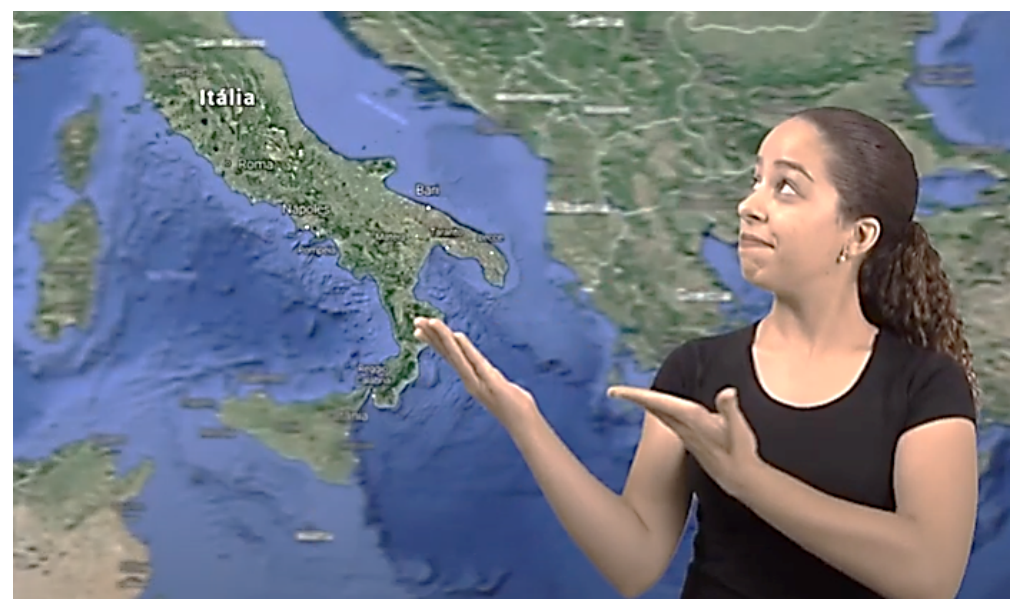

Fonte: vídeo didático em Libras elaborado pela tradutora (2018)

Figura 11 - vídeo 2 - Monarquia ( $3^{\mathrm{a}}$ versão)

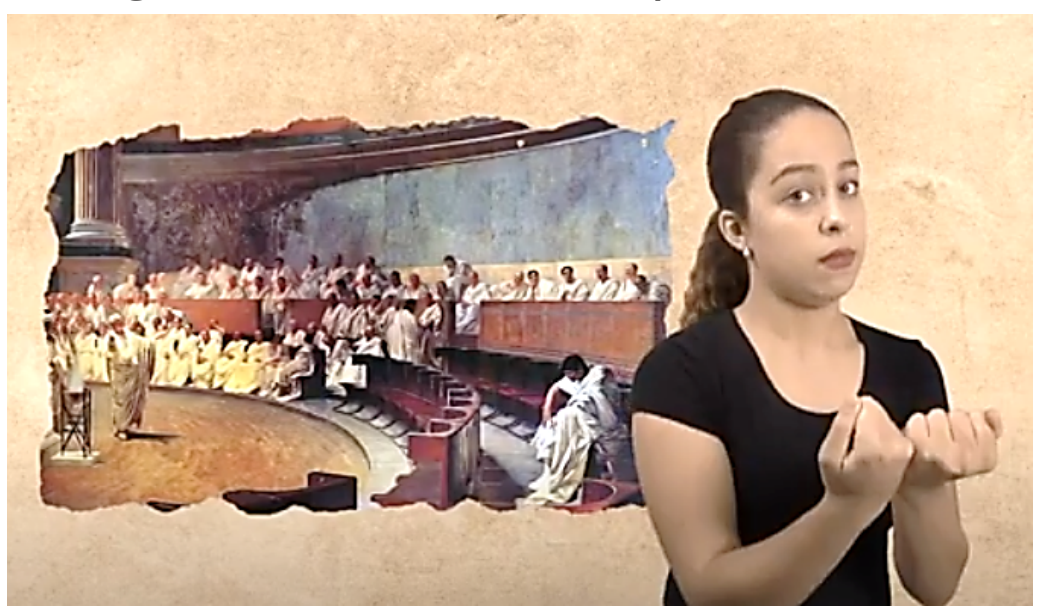

Fonte: vídeo didático em Libras elaborado pela tradutora (2018) 
Reflexões sobre materiais didáticos para alunos surdos: Roma Antiga em Libras Arlene Batista da Silva • Clara Marques Bodart

Figura 12 - vídeo 3 - Monarquia (3a versão)

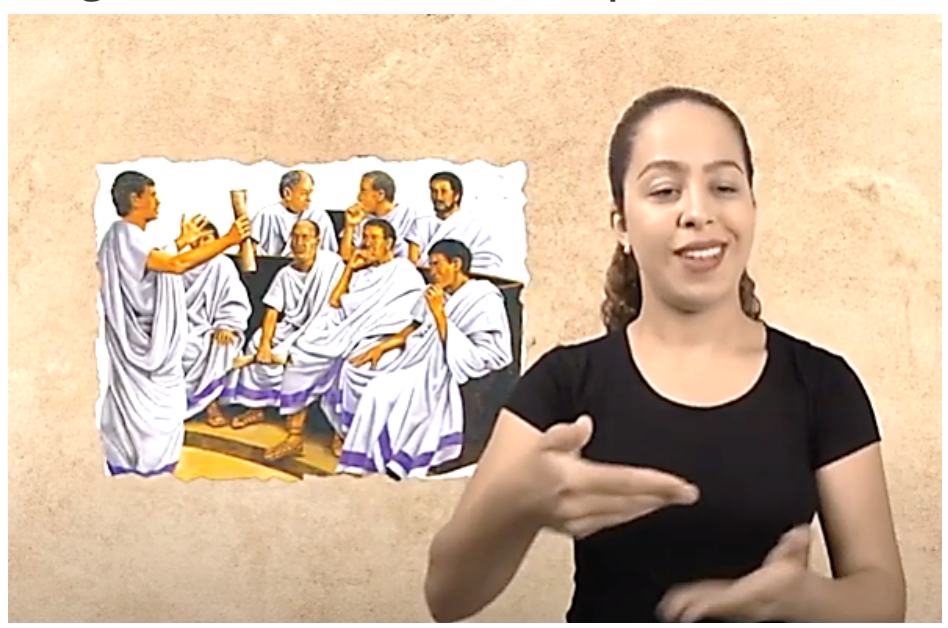

Fonte: vídeo didático em Libras elaborado pela tradutora (2018)

Figura 13 - vídeo 4 - Alto Império (3 ${ }^{\text {a }}$ versão)

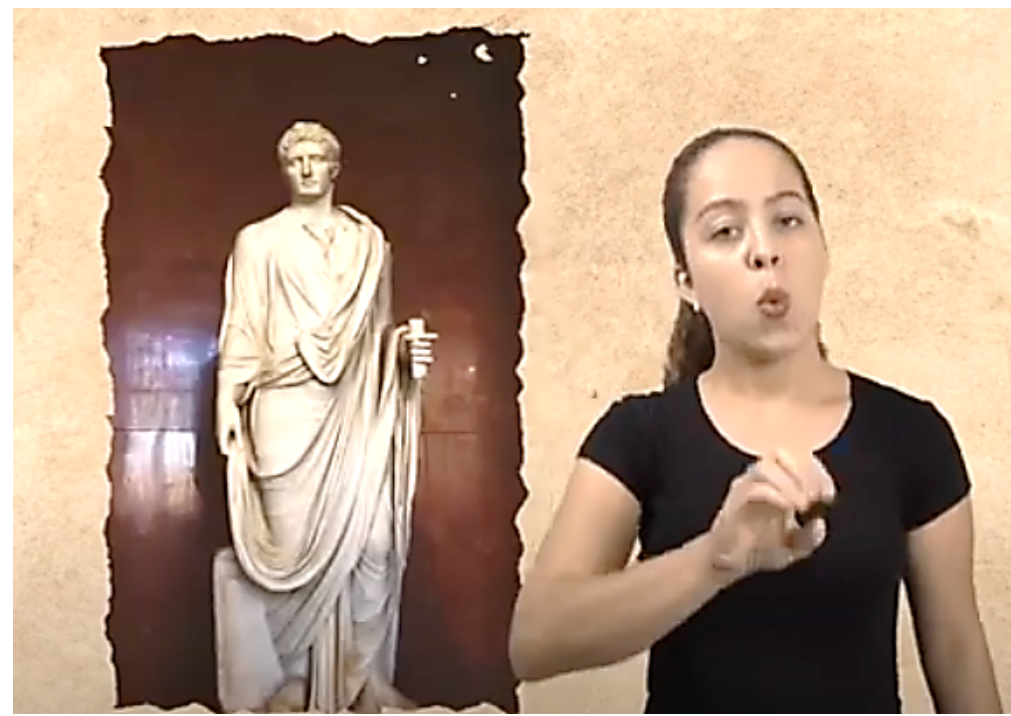

Fonte: vídeo didático em Libras elaborado pela tradutora (2018) 


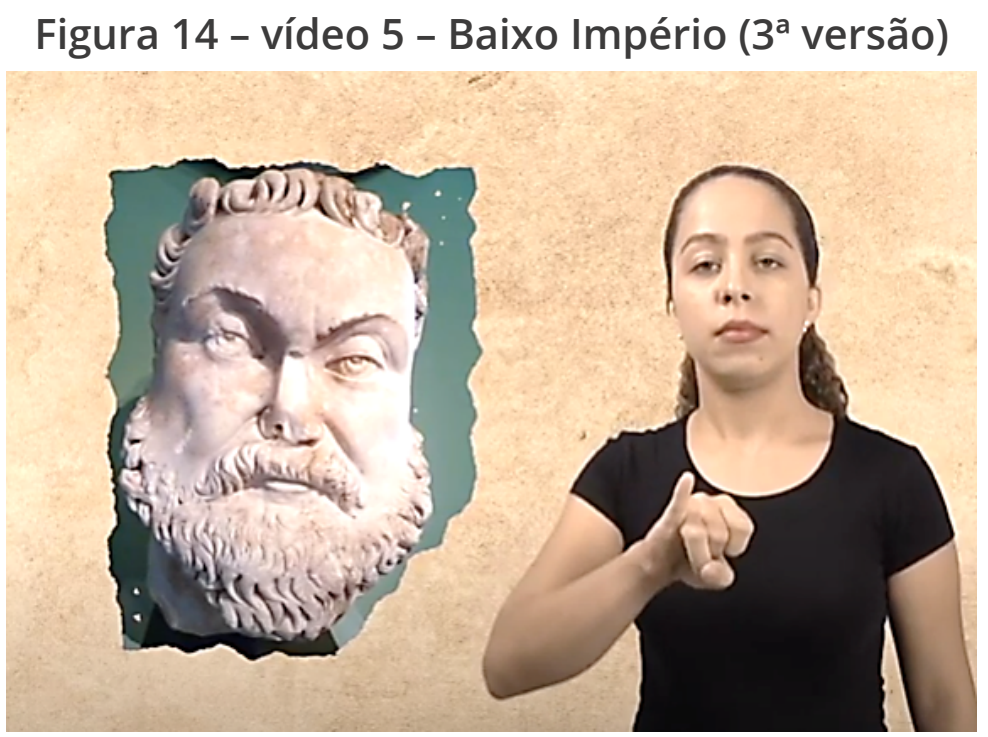

Fonte: vídeo didático em Libras elaborado pela tradutora (2018)

O tempo médio de duração dos cinco vídeos foi de dez minutos, com um conteúdo bem sucinto e objetivo. O roteiro da tradução privilegiou o conteúdo central dos textos registrados nos livros didáticos, abrindo mão de traduzir informações secundárias (ilustrações, pinturas, esculturas, infográficos, notas explicativas etc). Não significa dizer que não houve uma tradução "original", já que não houve equivalência, fidelidade total aos textos fonte. Houve, sim, uma tradução ou, conforme Sobral 2008, a criação de um transgênero, uma construção híbrida, composta por diversas vozes (do tradutor, dos professores, dos técnicos do INES, do monitor de audiovisual, das pesquisadoras) e linguagens verbo-visual, constituindo um todo orgânico, uma metamorfose que fez surgir um novo objeto cultural em Libras. Nas palavras de Sobral (2019):

A tradução produz um discurso alvo que reconhece o discurso fonte como seu mais importante parâmetro, mas que, para reconhecê-lo, tem de transformá-lo - legitimamente. O discurso fonte nasce numa dada interação e o discurso alvo em outra interação. E a tradução é a atividade transcultural que cria essa segunda interação e, assim, põe em contato duas interações, algo que amplia a rede de interlocução desencadeada pelo discurso fonte. (SOBRAL, 2019, p. 5-6). 
Reflexões sobre materiais didáticos para alunos surdos: Roma Antiga em Libras Arlene Batista da Silva . Clara Marques Bodart

Por fim, resta dizer que refletir sobre o processo de produção de materiais didáticos em Libras nos impeliu a discutir sobre os usos que se farão deles no contexto escolar. Nesse sentido, é preciso enfatizar que qualquer recurso pedagógico, para surdos ou ouvintes, sempre terá suas limitações. O vídeo, o filme e o livro são ferramentas de apoio para os professores trabalharem a partir da realidade cultural e social dos alunos. Portanto, a partir de Gumiero e Silva (2019), defendemos que não basta exibir os vídeos para os estudantes:

\begin{abstract}
É necessário criar situações que promovam experiências de leitura, o que significa, dentre outras coisas: ler para/com as crianças, desafiá-las à interpretação do texto, proporcionar-lhes o conhecimento de novas culturas, incentivá-las a relacionar os textos lidos com a realidade da vida [...]. (GUMIERO; SILVA, 2019, p. 372).
\end{abstract}

Desse modo, repudiamos qualquer uso dos materiais didáticos que excluam o professor desse processo, pois entendemos que eles são recursos auxiliares nas práticas de ensino. A nosso ver, os educadores são fundamentais para criar pontes entre os vídeos em Libras e os alunos surdos, para que eles possam se apropriar dos conhecimentos com direito de crítica e liberdade.

\title{
Conclusão
}

Este estudo teve como objetivo refletir sobre o processo de produção de um material didático em Libras, a fim de contribuir para a acessibilidade do estudante surdo e, ao mesmo tempo, construir um conhecimento teórico acerca da tradução desses objetos culturais. O conceito de tradução como atividade transcultural (SOBRAL, 2019), de reescritura (ARROJO, 1992), em interface com o conceito de gêneros discursivos de Bakhtin (2003), formaram o referencial teórico que norteou esta pesquisa. 
Reflexões sobre materiais didáticos para alunos surdos: Roma Antiga em Libras Arlene Batista da Silva • Clara Marques Bodart

Balizados por esses autores, buscamos respostas para as seguintes questões: a) Como traduzir conteúdos escolares em Libras de acordo com o nível linguístico do público surdo "real" matriculado no $6^{\circ}$ ano? b) Quais recursos utilizar para produzir um material audiovisual com uma arquitetônica que contribua para a aprendizagem dos alunos?

Primeiramente, podemos afirmar que a produção de materiais didáticos em Libras exige a interação entre diferentes agentes (tradutor, público-alvo, profissionais de audiovisual, designer gráficos etc.), com o fito de encontrar meios para solucionar problemas na composição do produto, de modo que o resultado final atenda às necessidades do aluno surdo. Nesse contexto, cabe ao tradutor estar conectado com toda a equipe, ouvir críticas, sugestões e estar disposto a reformular a tradução mais de uma vez se necessário, para obter um vídeo com qualidade.

Antes de "colocar a mão na massa", é preciso ouvir os alunos e professores, fazer um diagnóstico do ambiente escolar e da situação mais imediata de comunicação na qual o material didático será utilizado. Definido o tema e o objetivo da tradução, é fundamental criar um plano de ação que contemple: a) o tempo de execução; b) o levantamento de fontes de pesquisa; c) o roteiro de tradução; d) a gravação; e) a edição; f) a avaliação do produto pela equipe; g) as reformulações; h) a reavaliação do produto e i) a finalização e entrega do produto final ao público-alvo.

No desenvolvimento do plano de ação, o tradutor precisa avaliar a feitura da obra (que não se resume à atividade meramente linguística) e ser consciente de si, ou seja, de suas potencialidades e fragilidades, avaliando sua prática, as escolhas tradutórias e suas consequências internas e externas ao material didático.

Ressaltamos, por fim, que este estudo não pretende impor uma verdade absoluta ou inquestionável sobre a tradução de materiais didáticos em Libras, nem supomos haver encontrado a solução para um problema tão complexo. Defendemos que o tema carece ainda ser alvo de muitos estudos e análises, mas cremos 
Reflexões sobre materiais didáticos para alunos surdos: Roma Antiga em Libras Arlene Batista da Silva • Clara Marques Bodart

que os resultados aqui apresentados possam servir como ponto de partida para novas discussões e aprofundamentos.

Nessa perspectiva, concebemos este trabalho como um galo que sozinho não tece a manhã:

ele precisará sempre de outros galos.

De um que apanhe esse grito que ele

e o lance a outro; de um outro galo

que apanhe o grito de um galo antes

e o lance a outro; e de outros galos

que com muitos outros galos se cruzem

os fios de sol de seus gritos de galo,

para que a manhã, desde uma teia tênue,

se vá tecendo, entre todos os galos.

(NETO, 1968, p. 7).

Tal como no poema acima, nossa voz só terá sentido e força se seguir em frente, contando com outras vozes. E assim, nossas falas farão parte de manhãs, que, por certo, ajudarão a construir outras e outras, esperando que sejam o prenúncio da garantia efetiva dos direitos linguísticos dos sujeitos surdos.

\section{Referências}

ARROJO, R. Oficina de tradução: A teoria na prática. 2. ed. São Paulo: Ática, 1992.

BAKHTIN, M. Estética da criação verbal. Trad. Paulo Bezerra. 4. ed. São Paulo: Martins Fontes, 2003.

DERRIDA, Jacques. Des tours de Babel. In: GRAHAM, Joseph (Ed.). Difference in translation. Ithaca; London: Cornell University Press, 1985, p. 209-48.

FELIPE, T. A. Os processos de formação de palavras na libras. ETD Educação Temática Digital, Campinas, v. 7, n. 2, p. 200-217, jun. 2006. 
Reflexões sobre materiais didáticos para alunos surdos: Roma Antiga em Libras Arlene Batista da Silva . Clara Marques Bodart

FERNANDES, E. Linguagem e surdez. Porto Alegre: Artmed, 2003.

GUMIERO; D. G.; SILVA, A. B. Literatura Infantojuvenil impressa em Língua de Sinais: novos leitores, novos protocolos de leitura. Contexto/ Ufes, Vitória, n. 35, 2019. p. 356-376

JÚNIOR, A. B. História: Sociedade \& Cidadania, $6^{\circ}$ ano. 3. ed. São Paulo: FTD, 2015.

MEDVIÉDEV, P. N. O método formal nos estudos literários: introdução crítica a uma poética sociológica. Tradução de Sheila Camargo Grillo e Ekaterina Vólkova Américo. São Paulo: Contexto, 2012.

MOTOOKA, D. Y. Para viver juntos: História, $6^{\circ}$ ano. 1. ed. rev. São Paulo: Edições SM, 2009.

NETO, J. C. de M. - A educação pela pedra. In: Poesias Completas. Rio de Janeiro, Ed. Sabiá, 1968. p. 7-8.

NIDA, E.. Language, culture and translating. Shanghai: Foreign Language Press, 1993.

PINCHUK, I. Scientific and technical translation. Londres: Andre Deutch, 1977.

POPOVIC, A. The concept of "shift of expression" in translation analysis. In: HOLMES, J. S. (org.). The nature of translation: essays in the theory and practice of literary translation. Haia: Mouton, 1970. p. 78-87.

QUADROS, R. M.; KARNOPP, L. B. Língua de sinais brasileira: estudos linguísticos. Porto Alegre: Artmed, 2004.

RAMOS, C. R. Livro didático digital em Libras: uma proposta de inclusão para estudantes surdos. Revista virtual de cultura surda, Petrópolis: RJ. n. 11, p.1-11, julho de 2013.

SILVA, A. B. Literatura em Libras e educação literária de surdos: um estudo da coleção "Educação de Surdos" e de vídeos literários em Libras compartilhados na internet. 2015. 196 f. Tese (Doutorado em Letras) - Faculdade de Letras, Universidade Federal do Espírito Santo. Vitória, 2015. 
Reflexões sobre materiais didáticos para alunos surdos: Roma Antiga em Libras Arlene Batista da Silva . Clara Marques Bodart

SOBRAL, A. U. Da valoração intralinguística à transposição tradutória: um perspectiva bakhtiniana. Revista Cadernos de Tradução, UFRGS: Porto Alegre. Número especial, 2019. Disponível em: https://seer.ufrgs. br/cadernosdetraducao/issue/view/3837/showToc. Acesso em: 24 abr. 2020.

SOBRAL, A. U. Dizer o 'mesmo' a outros: ensaios sobre tradução. São Paulo: SBS-Special Book Services, 2008.

SOUSA, Wilma. A construção da argumentação da língua brasileira de sinais: divergência e convergência com a língua portuguesa. Tese (Doutorado em Linguística) - Faculdade de Letras, Universidade Federal da Paraíba, João Pessoa: UFPB, 2009.

THIOLLENT, Michel. Metodologia da pesquisa-ação. 18. ed. São Paulo: Cortez, 2011.

VICENTE, C.; VICENTINO, J. B. Projeto Mosaico - História, 6ªno. 2. Ed. São Paulo: Editora Scipione, 2016.

VINAY, J. P.; DARBELNET, J. Stylistique comparée du français et de I'anglais. Paris: Les Éditions Didier, 1958. 